\title{
Multimedia teaching CD-rom about energy sources
}

\author{
J. Casals-Terré ${ }^{1}$, R. Mujal-Rosas ${ }^{2}$, O. Boix-Aragonés ${ }^{2}$ and X. Salueña-Berna ${ }^{1}$ \\ ${ }^{1}$ Department of Mechanical Engineering \\ ETSEIT., Technical University of Catalonia UPC \\ C/ Colom 7-11 Terrassa 08222 SPAIN \\ phone:+34 937 398023, fax:+34 937 398022, e-mail: Jasmina.casals@upc.es \\ ${ }^{2}$ Department of Electrical Engineering \\ ETSEIT., Technical University of Catalonia UPC \\ C/ Colom 7-11 Terrassa 08222 SPAIN
}

\begin{abstract}
.
This paper introduces a new interactive teaching material developed in the Technical University of Catalonia for a multidisciplinary team of professors from different departments (electrical engineering, mechanical engineering and chemical engineering departments). This teaching tool has been created using the current technologies and will be offered in CD or DVD format This CD includes most of the actual used energies and analyses the state of the art of current and future energies sources (Fusion, Fuel cells, ....).

In summary, this is a didactic and scientific reference material, where in a single CD-ROM offers a complete vision of present and future power sources.
\end{abstract}

\section{Key words}

Renewable energies, Multimedia, teaching material.

\section{Introduction}

The idea of an interactive CD-ROM integrating most energies from conventional ones to renewable ones, appeared due to the necessity of having a teaching material suitable for the new educational needs in the university, for example distance education programs using information technologies as a learning tool. Although, this CD-ROM can be also used in class as a teaching tool, as far as in other levels of education.

Some of the contributions of this material are:

- Three different departments (Electrical engineering, mechanical engineering and chemical engineering) had been involved in the development of this tool. These departments include most of processes that take place in the power energy plants nowadays. Then, all energies had been studied from different points of view and with high accuracy.

- Initially, the subjects are explained clearly but without too details (this fact makes this material suitable to be used in courses were the students do not have previous knowledge), after that there is an accurate exposition of each energy source. The goal is having a scientific reference material in energy sources in electronic format suitable as elearning tool in this area.

- There is an interview section, where experts on each energy give their opinion on the thematic point treated in each energy (future, legislation, problems...). These interviews can be a video or just text.

- There is an hyperlink's section where the users can get in contact with the authors to offer opinions or to just ask for information.

- It is possible to present this information in different virtual platforms (web, CD, DVD...), allowing an easy way for the students to use this material at home.

- In each didactic unit there are interactive schemes, statistical data, interactive graphics that help the student to improve their understanding of the matter. Each unit is structured so it can be easily self-studied. At the beginning of each unit there are the objectives of the unit, and at the end a summary (usually in a graphical form) and an interactive quiz where the student can self-evaluate their level of understanding of the subject.

- The CD-ROM structure allows the user to study independently any energy source, without a preestablished order. For this purpose, each energy is treated separately including the study from its basic concepts, to its environmental problems or legislation.

- Several energies, which at present there is no general information in detail, such as geothermal energy or energies of marine origin, fuel cells... have been exposed carefully. Energies that in the future could cover most world-wide power necessities. 
- Legislation of the different countries as well as the criteria of convergence, and the pressures that are exerted on the official organisms (legally or economically), are summarized in form of interactive schemes that allow to see in a pleasant form, the present situation.

\section{2.- Contents .}

The goal of this CD was to have a self-studying material were student can learn the conventional energies, renewable energies and the last innovations in all energies. In summary the $\mathrm{CD}$ has the following points:

- History of the appearance and later use of the electrical energy. Problems faced by the first power plants, as well as the solutions that have been applied until the present.

- Present power necessities and forecasts of consumption for the next years.

- General concepts considered to have an economically and technically viable power plant

- Connection problems to grid of the different power sources.

- European legislation of electric generation of all type of power sources, as well as the criteria of convergence .

- General environmental aspects to be considered in each different type of source of energy generation.

- The conventional energies considered are the following ones: Hydroelectric energy, thermal energy and nuclear energy.

- The renewable energies considered are the following ones: wind energy, solar energy (thermal and photovoltaic), Biomass energy, Geothermal energy, Minihydroelectric energy and Marine power energy, experimental energies such as nuclear fusion, fuel cells, marine Hydrolysis....

- Final conclusions.

On each energy the following aspects are presented and analyzed:

- Historical review.

- Types of power plant facilities.

- Technical aspects.

- Principles of operation.

- Connection problems to the grid.

- Environmental problems and solutions

- Present situation.

- Legislation.

- Perspective of future.

- Conclusions.

- Summary and self-evaluation quiz.
The personnel involved in developing this project had been 5 professors from different departments ( 2 electrical engineering, 2 mechanical engineering and 1 chemical engineering), 3 scholarship students and a multimedia technician. The professors were in charge of the contents and mainly they had standard computer science knowledge (Office ${ }^{\circledR}$ package and specialized tools of its area). The scholarship students had a wide knowledge in drawing tools $\left(\right.$ CorelDraw $\AA$, Paint $\AA$, FireWorks ${ }^{\circledR}$, Autocad $\AA, 3 D$ studio $\AA$ ). They were in charge of edition of drawing, pictures and photos and in the integration of the content in the multimedia platform elaborated by the technician.

The multimedia technician advised in the election of needed software to make the integration of all the information. He taught the scholarship student with the knowledge of specific programs such as Macromedia ${ }^{\circledR}$ Flash ${ }^{\circledR}$, Fireworks ${ }^{\circledR}$, video edition...) and made and supervised the integration of the information in the chosen platform so that this one followed the usability guidelines [1].

The usability of a system, as a mean to do something (in his case learn some contents), has different aspects to be considered. On one side a system is usable if it is useful and moreover to be usable it has to be easy to learn how to use it.

In this sense we can define usability as the extent to which a product can be used by specified users to achieve specified goals with effectiveness, efficiency and satisfaction in a specified context.

\subsection{Equipment}

The equipment used in this project is the following:

- Software: -

-Macromedia Flash MX to design, program interactions nd assembly all the contents(diagrams, pictures, photos, text...) in the .platform.

- Autocad 3D modeling. -

- 3D Studio Max 4,2 Renderizing, 3d animations

- Pinnacle studio 8 Video Editing

- Hardware:

- Workstations Precision340 - PC pentium4 2 Ghz.

- Digital Camera

- Digital Video Camera : Sony Handycam Digital8

- Microphone

\section{4.- Methodology.}

Each professor was in charge of two or three different energies and for each energy the professor had to develop, summarize and select the contents that had to be included.

First step. The professor elaborated a Word $®$ file where appeared all the contents that have been described in the previous section This content was discussed and validated for all the professors.

\subsection{Personnel}


Second step After this validation process the professor had to select the way the information would be exposed to the student. In this step the multimedia technician exposed the different ways that were technically feasible to present the contents in an interactive CD.

Its is important to note that this step its is intrinsic to this type of material, because the typical teaching materials (books, notes,...) the information can be only text, pictures and photos.

After the professor decided the way the information would be presented and the contents were established all this information had to be assembled in a format accessible to all people that participated in the project.

To elaborate a methodology that allowed the understanding of the contents to all members involved in the project without need to be working simultaneously a PowePoint ${ }^{\circledR}$ slide with a layout similar to the one that the final CD platform would have was elaborated. This preliminary slide can be seen in the Fig 1 . The information contained in this slide was similar to the one that could be contained in the platform of the $\mathrm{CD}$, in other words, the same spacing and test font were used. The PowerPoint ${ }^{\circledR}$ program is a friendly program widely extended all personnel involved was familiar with it. This provided the ideal tool for the exchange of information.

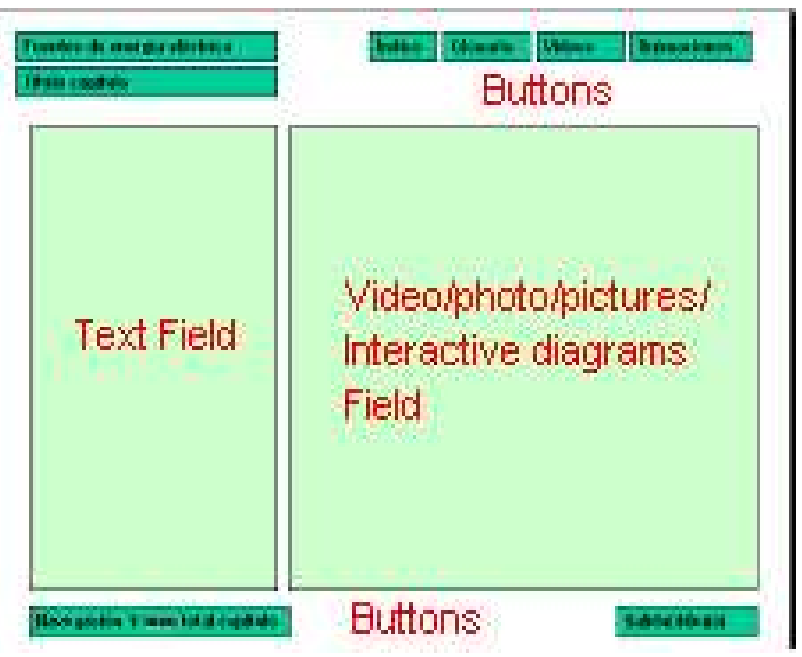

Figure 1 PowerPoint Slide layout

The slide has two great divisions, Figure 1: The text field of the left where the content is explained basically in text format. This field is used to explain or introduce the contents on the right of the slide. It can explain the way the information it is presented (how to navigate through this section). In the text field of the right there is the graphical content (schemes, photos, animations, interactions). If the slide has animation or interaction, the professor repeats the slide so many times as it is necessary changing the content of the field of the right so that it is reflected the different stages of the animation. The notes of the slide were used to make explanations of the operation of the interaction or to write the voice of the animations. Till now the two first parts of the figure 2 would have been done after that a parallel process started.

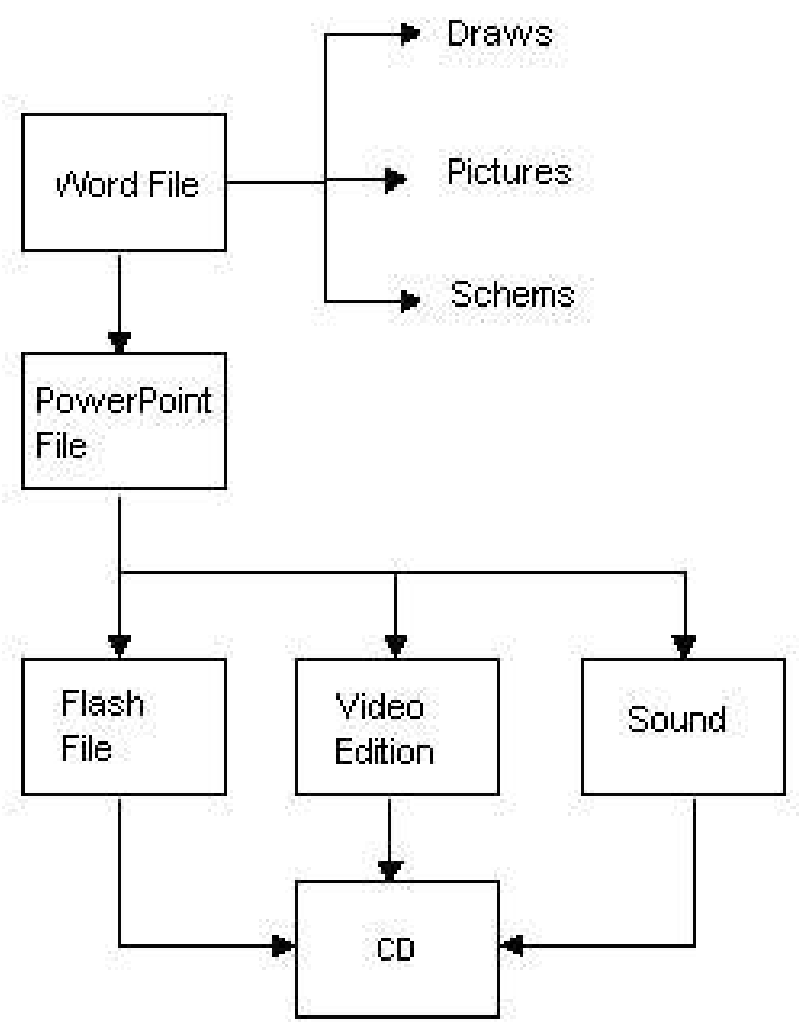

Figure 2 Information to be included in the $\mathrm{CD}$ for each energy

Third Step. The PowerPoint file with all the contents was distributed to the scholarship students in charge to develop the graphics and the animations according to the instructions given by the professors. The PowerPoint file offered the possibility to work asynchronously.

At this Point the platform created by the multimedia technician following the usability criteria was available to all the scholarship students that once they have the content (text and graphics), they included this content in the platform. As it can be seen in the figure 3 the Platform used was programmed using Macromedia Flash and with a layout similar to the Powerpoint slide.

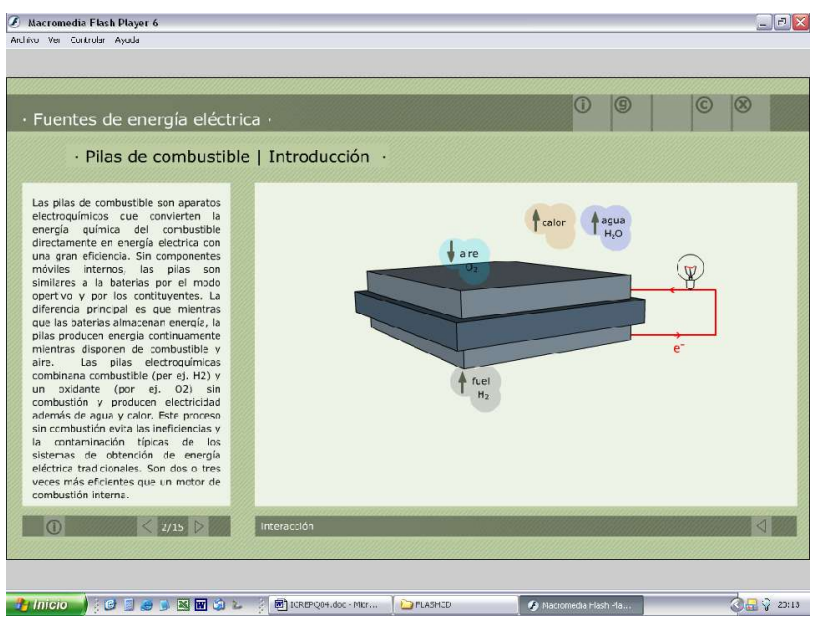

Figure 3 Layout of the interactive platform created used Macromedia Flash MX 
In Parallel, professors made different visits and interviews to experts in each area that served as source for videos explaining each energy. Some of this visits were all over the world (EEUU, United Kingdom, France and Italy and Spain) because some of the energy source are only exploted in this countries.

Finally, the explanations of the video were recorded following the directions of the professor and integrated in the video. Once all this process was done several meeting were done to validate the results. And after, the multimedia technician integrated all the video files in the platform.

For the edition of the video, and the voice, Pinnacle studio 8 software was used.

\section{5.- Platform}

The software Macromedia ${ }^{\circledR}$ Flash ${ }^{\circledR}$ MX was chosen to to develop the platform where all the contents would be placed. This software selected since it allowed simultaneously to integrate the different elements such as $3 \mathrm{~d}$ animations, $2 \mathrm{~d}$ animations, interactions, video, photos, pictures... See figure 3 to see the layout.

Following the usability criteria the colors and the navigation system was selected. We design a navigation system as simple as possible in order to make the system easy to use and efficient. In the figure 4, the zone assigned to navigation are marked in red.

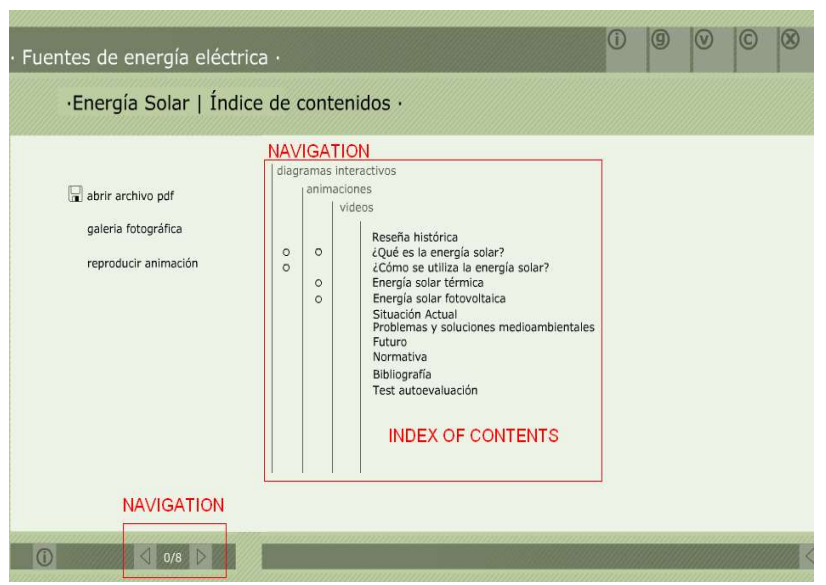

Figure 4 Navigation zones of the layout

In left part of the layout the user has two arrows that allow the user to go forward or backwards in the content. In the central part of the layout in red the index of contents is marked. In the index of contents the user has the possibility to go directly to the information desired. Moreover in the left of the index the user has information about what he will find in that part (interaction, animation, picture).

Once the user is in the selected section, see figure 5 , he has two possibilities of navigation: the first one, to return to the index pressing on the navigation button that indicates index or the second go forward or backward pressing the arrows on the right.

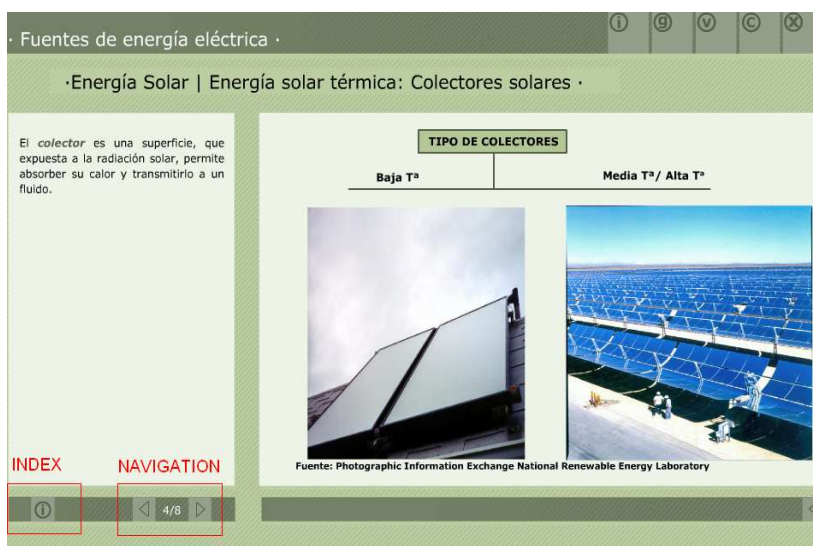

Figure 5 Navigation buttons in each section

\subsection{Adding contents.}

The platform also allowed us to add information in the same slide through the interaction. For example in the picture 6 and 7 two different information is visible depending if the user has the cursor on the first /second or third picture. This one and other types of interaction allow the author to extend the information and clarify ideas while the user navigates through it.

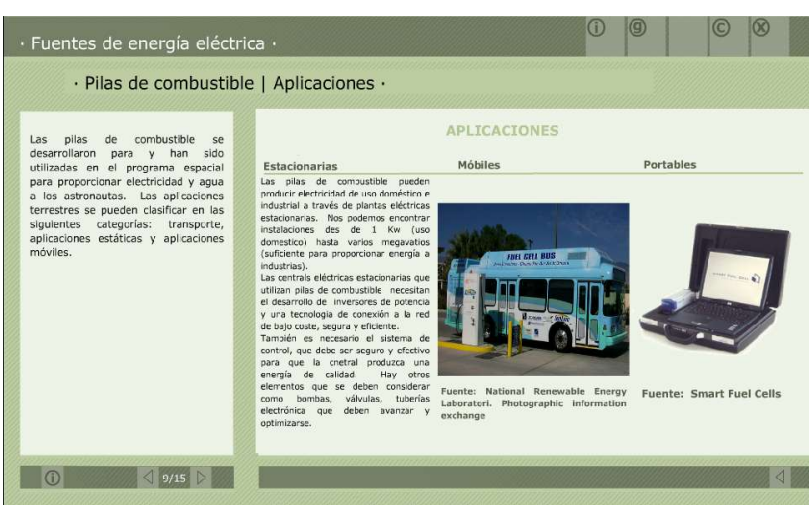

Figure 6 Information available when the user situates the cursor on the first picture

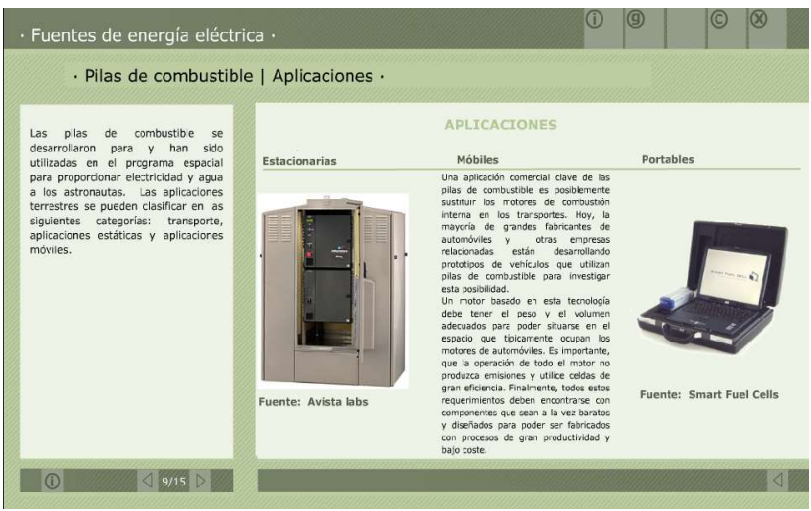

Figure 7 Information available when the user situates the cursor on the first picture

The professor in charge of this part would have facilitated the scholarship student, 6 slides in Powerpoint ${ }^{\circledR}$ in each 
one of which there would be the situation before and after the interaction, in figure 8 an example of this type of slide can be observed. In the notes of the slide, the interaction is explained, so the programmer knows how to do it and in the superior part it sees the text distribution and graphs.

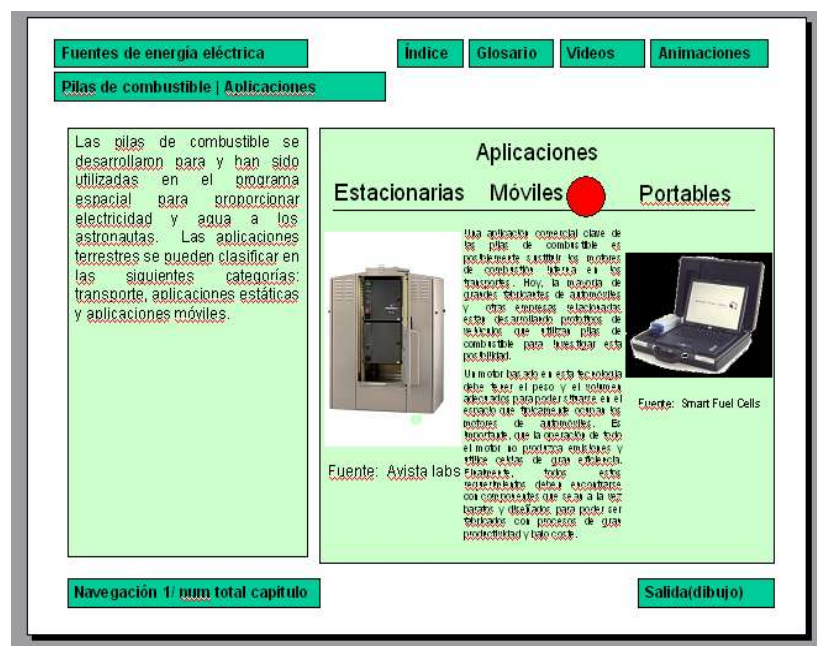

Figure 8 Layout of one slide with interaction

The scholarship students received this information and with no need to work jointly with the professor they programmed the interaction in the platform and integrated all the data, as the professor has displayed it in the slide. Although this process may seem a little long, since the professor first must compile the information in a word $\mathbb{R}$ file and after he must "translate" it to Powerpoint ${ }^{\circledR}$ file, is one of the most important. This process not only facilitates the work and the interaction between the people involved in the project in addition it is the starting point to generate the platform of the $\mathrm{CD}$.

\section{6.- Contents}

Examples of the contents in CD titled "Energy Sources" can be view in the following pictures.

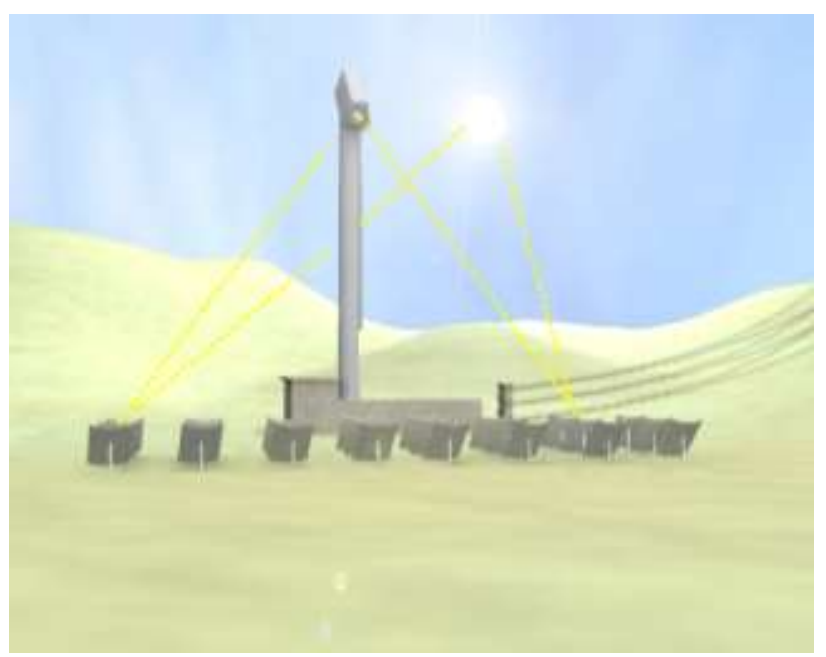

Figure 9 Scene of the Solar Tower Power Plant 3D Animation

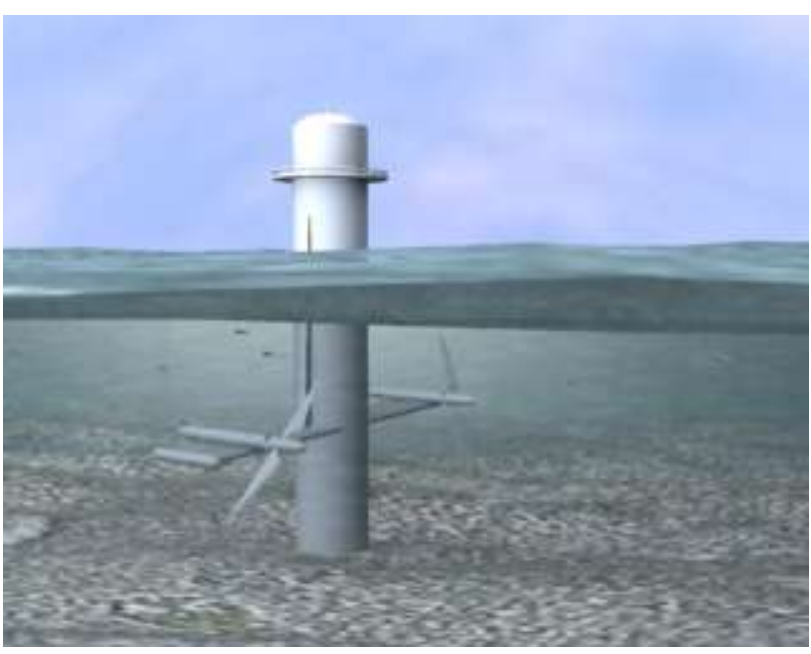

Figure 10 Scene of maritime energies.

\section{Conclusion}

Due to the fact that the thematic is very broad, it allows to give a generic approach to almost all contents related to electric energy generation.

On the other hand, the CD due to the variety of contents (videos, interactive schemes, photos, interviews to experts) becomes a useful material not only for university students it is also an educative tool professors and students of other educative levels. Moreover it is thought to be used not only as a in class material also as a selflearning tool at home.

Without a doubt this experience has been very enriching. It has put of relief an important aspect: it is not the same to prepare a content to be published in a book than to be published in a $C D$. In order to make a $C D$ the professor must make an additional work that consists of organizing the content so that it can be displayed to the student through schemes, drawings, photos.... This requires a considerable effort of organization the information in schemes, drawings, videos... Once it has been organized and chosen the information, it is important to use a program known by all the members of the equipment to transmit the information. The use of the Powerpoint ${ }^{\circledR}$ program with a design of slide equivalent (spaced, fonts....) to the one of the platform used in the CD has been very useful. This step in the creation process has offered the possibility to accelerate the work, allowing the work in parallel of all people involved in the project.

This project would not have been possible without the use of information technologies. Here, the role of LA FACTORIA an institution part of the Technical University of Catalonia that offers the possibility to use its equipment (software, hardware, digital camenras, microphones...) and there are experts that advice in each step of the project. The LA FACTORIA had an important role as advisor in all the steps and it is important to note that sharing the equipment between all the members of the University is much more efficient than having to invest in the same equipment in each new project. 


\section{Acknowledgement}

We would like to thank Thecnical University of Catalonia to support this activity and LA FACTORIA for the technical advice. Moreover we would like to thank all our students that have been involved in the project an without their invaluable help this project would not have been possible.

\section{References}

[1] DeborahJ. Mayhew. "The usability engineering lifecycle". Ed. Morgan Kaufman

[2] Nom ISO 9241 part 11 ISO/IEC 9241:

[3] R. Mujal "Planificación de proyectos de innovación docente y sus herramientas telemáticas". XI Congreso Universitario de Innovación Educativa en las Enseñanzas Técnicas. Vilanova i la Geltrú. 23-25 de Julio 2003

[4] "Monografias técnicas de energías renovables y convencionales". Progensa editorial.

[5] "Energías renovables y convencionales". Servicios de publicaciones de ICAEN

[6] "Centrales eléctricas y medioambiente" Servicios de publicaciones de ENDESA 